\title{
Dynamic Collision-Induced Dissociation (DCID) in a Quadrupole Ion Trap Using a Two-Frequency Excitation Waveform: I. Effects of Excitation Frequency and Phase Angle
}

\author{
Ünige A. Laskay \\ Center for Intelligent Chemical Instrumentation, Department of Chemistry and Biochemistry, \\ Ohio University, Athens, Ohio, USA
}

Jennifer J. Hyland

Department of Chemistry, University of Illinois, Urbana, Illinois, USA

\author{
Glen P. Jackson \\ Center for Intelligent Chemical Instrumentation, Department of Chemistry and Biochemistry, \\ Ohio University, Athens, Ohio, USA
}

\begin{abstract}
This study describes the application of a two-frequency excitation waveform to the end-cap electrodes of a quadrupole ion trap (QIT) during the mass acquisition period to deliberately fragment selected precursor ions. This approach obviates the need for a discrete excitation period and guarantees on-resonant excitation conditions without any requirement for resonant tuning; it is therefore faster than the conventional approach to collision-induced dissociation (CID) in QITs. The molecular ion of $n$-butylbenzene is used as thermometer molecule to determine the energetics of the new excitation procedure. The excitation waveform, consisting of two closely spaced sinusoidal frequencies, has an interference pattern that displays nodes and crests in the time domain. The energetics (determined by the product ion ratios of 91/92 Th) and CID efficiencies are highly dependent on the excitation amplitude, the relative position of the excitation frequencies in the Mathieu stability diagram, and whether the ions come into resonance during a node or crest of the excitation waveform. Under highly energetic conditions, ratios of $91 / 92$ as large as 15 can be obtained at concomitant CID efficiencies of $10 \%$, indicating internal energies in excess of $10 \mathrm{eV}$ at the time of fragmentation. These extremely high internal energies far exceed the energetics achievable using conventional on-resonance excitation in QITs, indicating that the collisional heating rate is very fast in the new approach. Under less energetic conditions CID efficiencies as high as $70 \%$ are possible, which compares favorably with results obtained by conventional on-resonance excitation. Correlation analyses are used to determine the conditions that simultaneously optimize energetic and efficient fragmentation conditions. (J Am Soc Mass Spectrom 2007, 18, 749-761) (C) 2007 American Society for Mass Spectrometry
\end{abstract}

$\mathrm{T}$ The ever-increasing need for reliable mass spectrometric data drives researchers to develop increasingly sophisticated instruments that allow fast, cost-effective, and reproducible analysis of a wide variety of samples. Quadrupole ion traps (QITs) are of significant interest in the achievement of this goal because of their flexibility and excellent sensitivity. The ability to isolate precursor ions [1-3], effect fragmenta-

Published online February 1, 2007

Address reprint requests to Dr. Glen P. Jackson, Department of Chemistry and Biochemistry, Ohio University, 136 Clippinger Laboratories, Athens, OH 45701-2979, USA. E-mail: jacksong@ohio.edu tion [4-6], and to detect trapped ions in a variety of methods [7-9] makes QITs a very useful tool in many applications [10, 11]. The design of faster, more sensitive ion traps that allow coupling with fast separation methods and overcome the necessity for resonance tuning is a major issue for QIT developers. The present study describes a small step toward the long-term goal of achieving fast, simple, and reliable tandem mass spectrometry (MS/MS).

The use of QITs in tandem mass spectrometric experiments is made possible through on-resonance excitation [12], also known as axial modulation. Excitation is usually performed by matching the frequency of 
motion of a selected ion with a supplemental frequency applied to the end-cap electrodes. When on-resonance conditions are achieved, the amplitude of the ion motion increases. This kinetic excitation leads to energetic collisions with the bath gas, to the conversion of kinetic to internal energy, and, ultimately, to fragmentation $[13,14]$. Although this approach permits the fragmentation of successive selected precursor ions $\left(\mathrm{MS}^{n}\right)$ [5], the difficulty of achieving on-resonance conditions leads to irreproducible fragmentation spectra between experiments, instruments, or laboratories. In selected applications, conventional on-resonance excitation can be slow relative to the timescale of fast separation methods, which can limit the sampling frequency or number of data points per chromatographic peak. Therefore, fragmentation procedures that can reduce the timeframe required for tandem mass spectra acquisition are desirable [15-17].

When the resonant excitation amplitude is large enough to overcome the Dehmelt pseudopotential well depth [18], resonant ejection may compete with or supersede resonance excitation $[6,19]$. If ions are deliberately resonantly ejected during mass acquisition, the $\mathrm{q}_{\mathrm{z}}$ value at which ions are excited can be selected to provide the desired mass-range extension $[9,20,21]$. The increase in kinetic energy required for ion ejection can cause the ions to undergo energetic collisions with the bath gas before ejection and can lead to fragmentation of the selected precursor. This process can produce undesired features in the mass spectrum, such as peak fronting [22], ghost peaks [23], and mass shifts [24], leading to complicated, misleading, or poor-resolution mass spectra. Previous studies investigated the influence of scan direction [25-27], resonance ejection frequency [27], and axial modulation amplitudes [28] on the mass spectra of fragile ions during the mass instability scan. Although unintentional fragmentation of precursor ions during axial modulation has generally been shown to be detrimental, it was previously shown $[29,30]$ that deliberate fragmentation of precursor ions during mass acquisition can be used to provide reliable fragmentation spectra of the precursor ions. For example, product ions can be recaptured and detected at their corresponding $\mathrm{m} / \mathrm{z}$ values as long as their $\mathrm{m} / \mathrm{z}$ value is above the low mass cutoff (LMCO) at the time of fragmentation.

Our group recently demonstrated that collision-induced dissociation (CID) efficiencies as large as $60 \%$ and internal energies up to $7 \mathrm{eV}$ can be achieved with the application of a single-frequency excitation waveform applied to the end-cap electrodes during mass acquisition, in addition to the axial modulation frequency [30]. As the ions are swept through the stability diagram by gradually increasing the radio-frequency (rf) amplitude on the ring electrode, each ion comes into resonance with the applied fixed-excitation frequency at a specific time during the scan. The on-resonance condition-as in the case of axial modulation-causes an increase in the oscillation amplitude of the ions and results in energetic collisions with the bath gas. It was observed [30] that at low excitation amplitudes, precursor ions gain only a small amount of internal energy and fragment with less energy and poorer efficiencies. At large excitation amplitudes, the ions were accelerated beyond the Dehmelt pseudopotential well depth, resulting in ion ejection and poorer CID efficiencies. In this case, however, larger internal energies were possible, as witnessed by the distribution of fragment ions that were collected in low abundance. Judicious selection of the excitation frequency and amplitude resulted in both efficient and energetic fragmentation of the precursor ions.

Our findings naturally led us to consider excitation using multiple-frequency waveforms in an attempt to increase the CID efficiencies and achieve larger internal energies before fragmentation. In the excitation method proposed herein, a second frequency is used in an effort to provide additional excitation of the precursor ions, without changing the scan rate or timescale of the experiment. In this multiple-frequency excitation approach, the ions' secular frequencies are swept through the fixed frequencies of excitation as in the previously reported study [30]. The superimposition of the two sinusoidal frequencies results in an excitation waveform with a beating pattern. As the secular frequency of the precursor ions is swept through the stability diagram, the ion is resonantly excited by the resulting waveform and fragmentation occurs. Larger internal energies are expected if the two frequencies work constructively to impart more internal energy to the ions than is possible using the single-frequency excitation. This process will depend on the applied frequencies and their amplitudes and phase relationships.

Here, we investigate the fragmentation of the $n$-butylbenzene because of its well-known fragmentation energetics [31-37]. The fragment ion at $91 \mathrm{Th}$ is the result of the direct cleavage of the 134 Th precursor ion, which occurs at relatively high internal energies $(\sim 1.7 \mathrm{eV})[37,38]$, whereas the fragment ion at 92 Th appears at low internal energies $(\sim 1.0 \mathrm{eV})[37,38]$ as the result of a McLafferty rearrangement. The ion ratios of 91/92 are a direct measure of the internal energy deposited during CID; the internal energy deposited during the experiment can be estimated with the aid of a calibration curve relating the ratio of the two fragment ions to the average internal energy of the precursor ion using more precise spectroscopic methods $[33,34]$. In this report, effects of the phase angle and excitation amplitudes are shown.

The working frequencies, excitation amplitude, phase angle, and the scan rate were studied in a systematic manner. Results obtained when varying the frequency spacing and the scan rate will be presented in a future publication.

\section{Experimental}

\section{Instrumentation}

All experimental data were collected with a Thermo Finnigan Polaris $Q$ quadrupole ion trap mass spectrom- 
eter (San Francisco, CA, USA). The undiluted n-butylbenzene (99\% purity, Sigma-Aldrich, St. Louis, MO, USA) was placed in a glass vial and positioned in a trace gas chromatography (GC) oven at $50{ }^{\circ} \mathrm{C}$. The headspace of about $2 \mathrm{~mL}$ of the compound was sampled at a controlled rate through the GC transfer line using a $30-\mu \mathrm{m}$ inner-diameter silica capillary. The unmodified electroionization (EI) source was used for ion formation. The automatic gain control (AGC) function was disabled and the ion injection time was carefully selected before each experiment to ensure that the precursor ion abundance remained constant between experiments. As will be reported in a subsequent paper, the ion abundance appears to have some, but as-yet unknown, effect on the energy deposited to the precursor ions during this novel excitation procedure.

As $^{\circ}$ previously ${ }^{\circ}$ reported $^{\circ}[30]^{\circ}$, our $^{\circ}$ group $^{\circ}$ used $^{\circ}$ Visual Basic ${ }^{\circledR} 6.0$ (Redmond, WA, USA) software command programs provided by Thermo to generate an arbitrary waveform that can be applied at any period of QIT operation. In the present work, a two-frequency sumof-sines ${ }^{\circ}$ waveform $^{\circ}[4]^{\circ}$ was $^{\circ}$ applied $^{\circ}$ to $^{\circ}$ the $^{\circ}$ end-cap electrodes in a dipolar fashion during mass acquisition. Experiments were performed wherein the phase angle and the amplitude of the two frequencies were systematically studied in a series of sequence-looped experiments. One sequence consists of ion formation, isolation, and mass acquisition with the two-frequency excitation waveform at a given set of conditions. The raw spectra are recorded in raw (XCalibur) format and selected parent and product ion abundances are exported into a Microsoft Excel spreadsheet in real time. The next sequence is automatically performed by the software wherein the same frequencies are applied, but at a different phase angle or amplitude. The initial, final, and step values of these parameters can be defined at the beginning of the experiment. Product-ion spectra were obtained at excitation amplitude intervals of $0.1 \mathrm{~V}_{\mathrm{pp}}$ from 0 to $18 \mathrm{~V}_{\mathrm{pp}}$, and at phase angle intervals of $5^{\circ}$ from 0 to $360^{\circ}$. Contour plots were constructed in Origin $^{\circledR}$. Each set of sequence-looped experiments consists of 13,213 different experimental conditions; the data acquisition was achieved in roughly $9 \mathrm{~h}$, depending on the ionization time.

The CID efficiency values were calculated relative to the total ion current (TIC) occurring at $0 \mathrm{~V}_{\mathrm{pp}}$ excitation amplitude (corresponding to the precursor ion signal). At low excitation amplitudes, the TIC is made up exclusively by the precursor ion signal because the ions are trapped in stable trajectories and no ion losses are observed before detection. By using the TIC of the highest value recorded in each sequence of experiments, one ensures that scattering losses in a direction different to the detector-and thus do not show up in the mass spectrum-are correctly taken into account. The product ion ratios of 91/92 were calculated only when the ion recoveries exceeded a prespecified value ( $\sim 10$ times the noise). For the CID efficiency and 91/92 ion ratio calculations, a rolling average of five data points was performed in the amplitude dimension before graphing. To identify conditions for the simultaneous occurrence of highly efficient and highly energetic fragmentation, a covariance analysis was performed ${ }^{\circ}$ by ${ }^{\circ}$ multiplying ${ }^{\circ}$ the ${ }^{\circ} z$-scores ${ }^{\circ}[(x-\bar{x}) / \sigma]^{\circ}[39]^{\circ}$ for the CID efficiency and 91/92 ratios at each data point.

ITSIM 5.0 simulation software from the Cooks research group at Purdue University was used to simulate the experiments $[40] . T^{\circ}$ Th $^{\circ}$ deling $^{\circ}$ was based ${ }^{\circ}$ on initial conditions of 20 precursor ions of $n$-butylbenzene ions at $300 \mathrm{~K}$ with a hardsphere cross section set at $0.5 \mathrm{~nm}^{2}$. The bath gas was helium at a pressure and temperature of $1 \mathrm{mTorr}$ and $300 \mathrm{~K}$, respectively. Integration parameters were set as follows; method: fourth-order RungeKutta; integration step: 10 ns; collision probability: hardsphere model with random-angle-scattering enabled; internal energy calculated from the amplitude of the average of collisions, which was not influenced by the ejection of a few the excited ions. The primary rf voltage was ramped to eject ions from 40 to $150 \mathrm{Th}$ at a fixed frequency of $1.03 \mathrm{MHz}$. Dipolar excitation was applied at the desired voltage and frequency for the duration of the mass acquisition step (20 ms). The resulting enveloped data were exported to Excel for plotting. Fourier analyses of the simulations were also performed using the ITSIM software to analyze the relative amplitudes of motion of the ions in the dynamic CID simulations. For further discussion on simulation parameters ${ }^{\circ}$ refer $^{\circ}$ to $^{\circ} \mathrm{Bui}^{\circ}$ and $^{\circ} \operatorname{Cooks}^{\circ}[40]$.

\section{Results and Discussion}

To understand the excitation of ions using a twofrequency excitation waveform in the dynamic collision-induced dissociation (DCID) approach, it helps to generate a physical vision of the excitation process. Figure $^{\circ} 1^{\circ}$ shows $^{\circ} \mathrm{a}^{\circ}$ selected $^{\circ}$ period $^{\circ}$ of ${ }^{\circ}$ the $^{\circ}$ excitation $^{\circ}$ waveform resulting from the superposition of two sinusoidal frequencies of $\omega_{1}=171$ and $\omega_{1}=172 \mathrm{kHz}$ at $1 \mathrm{~V}$ amplitude and 0 and $180^{\circ}$ relative phase angles. The consequent trigonometric relation- $\sin \left(\omega_{1}\right)+\sin \left(\omega_{2}\right)=$ $2 \sin \left(\left[\omega_{1}+\omega_{2}\right] / 2\right) \cos \left(\left[\omega_{1}-\omega_{2}\right] / 2\right)$-results in an interference pattern with a main frequency component at $\left(\omega_{1}\right.$ $\left.+\omega_{2}\right) / 2=171.5 \mathrm{kHz}$ which is modulated at a frequency of $\left(\omega_{1}-\omega_{2}\right) / 2=0.5 \mathrm{kHz}$. The sum-of-sines waveform therefore ${ }^{\circ}$ has $^{\circ}$ nodes $^{\circ}\left(\right.$ labeled $^{\circ} \mathrm{A}^{\circ}$ in $^{\circ}$ Figure $\left.^{\circ} 1 \mathrm{a}\right){ }^{\circ}$ and $^{\circ}$ crests (labeled ${ }^{\circ} \mathrm{B}^{\circ}$ in $^{\circ}$ Figure $\left.^{\circ} 1 \mathrm{a}\right),{ }^{\circ}$ but $^{\circ}$ Fourier $^{\circ}$ analysis $^{\circ}$ of ${ }^{\circ}$ the waveform can be used to reveal the presence of the two constant-amplitude excitation frequencies. Although ions are capable of picking up a small amount of kinetic energy from an excitation waveform that is off-resonance, the gains in kinetic energy are considerably enhanced during resonance conditions. When the two excitation frequencies are similar, the ions will be able to pick up kinetic energy simultaneously from both frequencies. For this reason, the timing of when the frequency of ion motion comes into resonance with the excitation waveform will be crucial in determining the amount of kinetic energy gained by the ions. For 


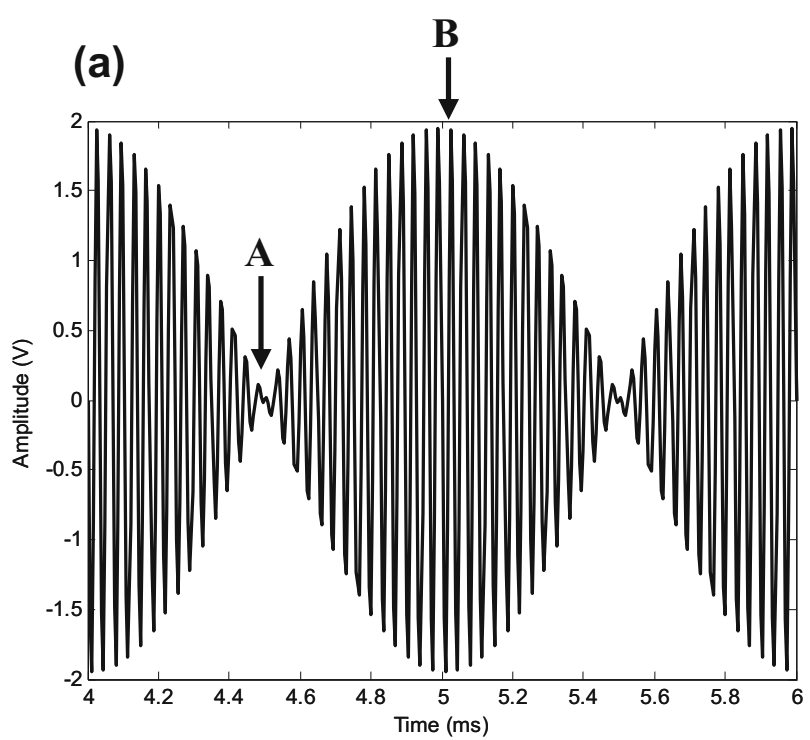

(b)

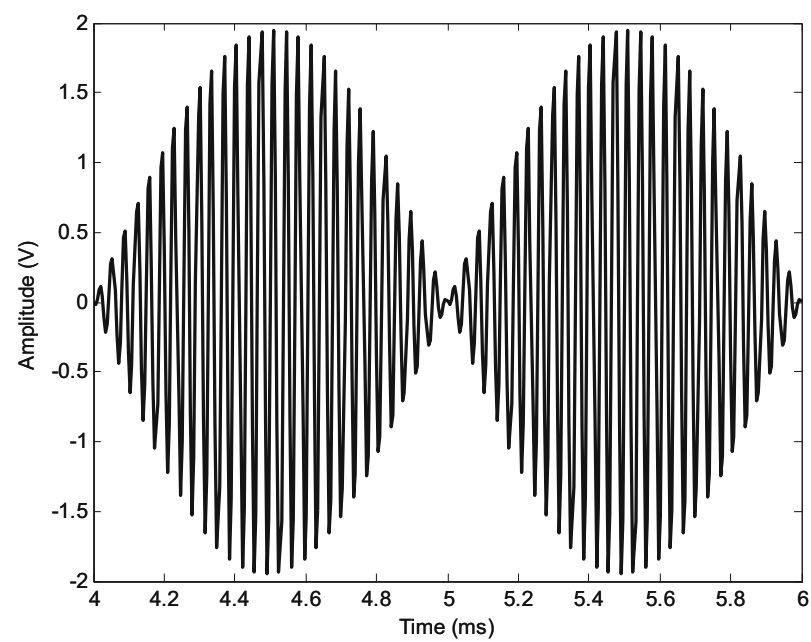

Figure 1. Waveform constructed by the superimposition of 171- and 172-kHz sinusoidal frequencies each of $1-\mathrm{V}$ amplitude at relative phase angles of (a) $0^{\circ}$ and (b) $180^{\circ}$.

example, if the ions' secular frequency approaches resonance conditions during a maximum in the beat-

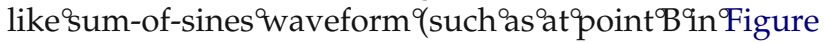
1a), ${ }^{\circ}$ larger $^{\circ}$ kinetic $^{\circ}$ energy $^{\circ}$ depositions $^{\circ}$ are $^{\circ}$ possible. However, if the ions come into resonance during a node in $^{\circ}$ the ${ }^{\circ}$ interference ${ }^{\circ}$ pattern $^{\circ}\left(\right.$ such $^{\circ}$ as $^{\circ}$ point $^{\circ} \mathrm{A}^{\circ}$ in ${ }^{\circ}$ Figure 1a), ${ }^{\circ}$ the ${ }^{\circ}$ ions ${ }^{\circ}{ }^{\circ}$ ill $^{\circ}$ be $^{\circ}$ excited $^{\circ}$ to $^{\circ} a^{\circ}$ lesser ${ }^{\circ}$ extent. ${ }^{\circ}$ After ${ }^{\circ}$ the conversion of kinetic to internal energy by collisions with the bath gas, the fragmentation efficiency and energetics of the precursor ions will depend on the degree of kinetic excitation. In certain cases, if the kinetic energy of the ion is too large, the ions will be resonantly ejected at the time of excitation and little or no fragmentation will be observed, as is the case for conventional on-resonance excitation. The fragmentation efficiencies and energetics of the precursor ions may thus be fine-tuned by judicious selection of the two excitation frequencies and their relative phase angles.

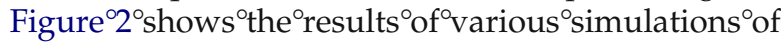
the mass instability scan when the primary rf-trapping potential is ramped from LMCO $40-150$ Th at the experimental scan rate of $5.5 \mathrm{Th} / \mathrm{ms}$. The total average kinetic energy of the 20 simulated ions is plotted as a function of time. Using the ITSIM software, it is also possible to perform a Fourier analysis of the z-kinetic energy to help understand the frequencies at which the kinetic energy of the ions is most enhanced. If an excitation amplitude of $0 \mathrm{~V}$ is applied during the mass acquisition ramp (data not shown), the fast Fourier transform (FFT) spectrum shows no well-defined peak maximum in the z-velocities, as expected. If an excitation waveform consisting of $171 \mathrm{kHz}$ is applied to the end-cap ${ }^{\circ}$ electrodes ${ }^{\circ}$ during $^{\circ}$ mass $^{\circ}$ acquisition ${ }^{\circ}$ Figure $^{\circ} \mathrm{a}$ ), the ions can be seen to undergo kinetic excitation shortly after $5.0 \mathrm{~ms}$ when the ions' secular frequency momentarily matches the frequency of the excitation waveform. FFT analysis of the ion motion in the simulations (data not shown) indicates that the z-velocity of the ions increases primarily at $171 \mathrm{kHz}$, again indicating that kinetic excitation occurs only during the short period of resonance between the ions' dynamic secular frequency and the fixed-excitation frequency.

Figure $^{\circ} 2 \mathrm{~b}^{\circ}$ shows ${ }^{\circ}$ that ${ }^{\circ}$ when ${ }^{\circ}$ the ${ }^{\circ} n$-butylbenzene ${ }^{\circ}$ precursor ions are excited at a frequency of $172 \mathrm{kHz}$ during the mass instability scan, the ions also pick up kinetic energy when they have a similar secular frequency of motion to the excitation waveform-in this case a little later than when the excitation waveform was at 171 $\mathrm{kHz}$. Figure 2c $\mathrm{c}^{\circ}$ hows the $^{2}$ total kinetic $^{\circ}$ energy ${ }^{\circ}$ of the ions when excitation frequencies of 171 and $172 \mathrm{kHz}$ are applied simultaneously to the end-cap electrodes during mass acquisition at a relative phase angle of $0^{\circ}$. The interference ${ }^{\circ}$ pattern ${ }^{\circ}$ thus $^{\circ}$ corresponds $^{\circ}$ to ${ }^{\circ}$ Figure ${ }^{\circ} 1 \mathrm{a}$. It ${ }^{\circ}$ is evident ${ }^{\circ}$ that ${ }^{\circ}$ applying ${ }^{\circ}$ two $^{\circ}$ frequencies ${ }^{\circ}\left(\text { Figure }^{\circ} 2 \mathrm{c}\right)^{\circ} \mathrm{Can}$ result in more kinetic energy of the ions compared to the ${ }^{\circ}$ cases $^{\circ}$ when $^{\circ}$ ust ${ }^{\circ}$ one ${ }^{\circ}$ waveform ${ }^{\circ}{ }^{\circ}$ applied ${ }^{\circ}$ (Figure $2 \mathrm{a}$ and b). It is interesting to note that the maximum kinetic energy is gained slightly earlier in the mass acquisition ramp than when either of the two excitation frequencies is in resonance with the secular frequency of motion of the precursor ions. If one compares the simulations in Figure ${ }^{\circ} 2 \mathrm{c}^{\circ}$ to $^{\circ}$ the ${ }^{\circ}$ excitation ${ }^{\circ}$ waveform ${ }^{\circ}$ under $^{\circ}$ these ${ }^{\circ}$ conditions ${ }^{\circ}$ in $^{\circ}$ Figure $^{\circ} 1 \mathrm{a},{ }^{\circ}$ one ${ }^{\circ} \mathrm{Can}^{\circ}$ see $^{\circ}$ that ${ }^{\circ}$ the $^{\circ}$ maximum ${ }^{\circ}$ in the z-kinetic energy at $5.0 \mathrm{~ms}$ matches well with the crest in the interference pattern at point $B$ of the excitation ${ }^{2}$ waveform. Figures $2 d^{\circ}{ }^{\circ}{ }^{\circ} 1 b^{\circ}$ show ${ }^{\text {th }}$ at ${ }^{2}$ when the phase angle of the excitation frequency at $172 \mathrm{kHz}$ is shifted to $180^{\circ}$, the ions come into resonance close to a node in the excitation waveform. The ions are therefore

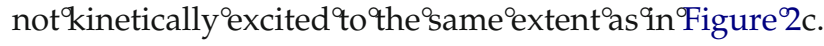

The kinetic excitation discussed above has a strong influence on the internal energy of the ions, which 
ultimately determines the extent and nature of fragmentation of the ions. Figure $3{ }^{\circ}$ is $^{\circ}$ a $^{\circ}$ plot $^{\circ}$ of ${ }^{\circ}$ the ${ }^{\circ}$ simulated internal energy gained by the $n$-butylbenzene ions as a
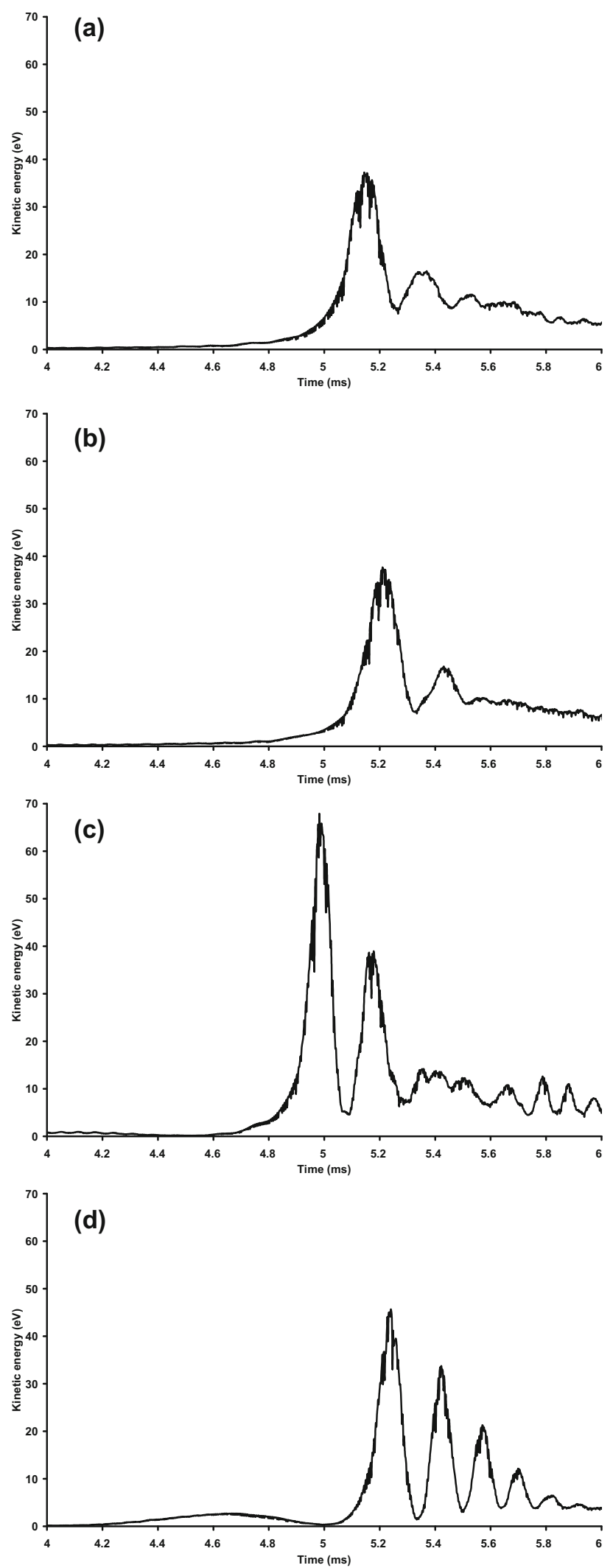

function of time to show that the internal energy gain is also highly dependent on the initial phase angle between the two excitation frequencies. In these simulations, the internal energy of the ions is greatest when the ions come into resonance during a crest in the excitation waveform, that is, at $0^{\circ}$ initial phase angle between the excitation frequencies at 171 and $172 \mathrm{kHz}$. Conversely, the internal energy gained by the precursor ions is smallest when the ions come into resonance during a node in the excitation waveform, that is, at an initial phase angle of $180^{\circ}$. At an initial phase angle of $90^{\circ}$ between the two excitation frequencies, the internal energy gain is almost identical to the internal energy gain when excitation is performed using a singlefrequency excitation at either 171 or $172 \mathrm{kHz}$. In short, the simulations show that there is a strong dependency between the phase of the two excitation frequencies and the kinetic or internal energy gained by the precursor ions. The phase relationship between the two excitation frequencies determines whether the on-resonance condition occurs at a node or a crest in the excitation waveform, or somewhere in between. The excitation frequencies can therefore work constructively, to impart more energy to the ions than can be gained by a single-frequency excitation waveform, or destructively, to impart less energy to the ions than can be gained by single-frequency excitation.

Figure $4{ }^{\circ}$ shows the ${ }^{\circ}$ experimentally ${ }^{\circ}$ determined product-ion mass spectra when the second frequency of a two-frequency waveform is applied at different initial phase angles relative to the first excitation frequency. Again, the initial phase angle of each frequency is defined relative to each other at the start of the mass acquisition scan; it is purely an experimentally defined variable and it is not intended to suggest any known phase $^{\circ}$ relationship $^{\circ}$ with $^{\circ}$ the $^{\circ}$ ion $^{\circ}$ motion. ${ }^{\circ}$ Figure $^{\circ} 4$ a displays the mass spectrum when a waveform consisting of 171 and $172 \mathrm{kHz}$ is applied at an amplitude of 4 $\mathrm{V}_{\mathrm{pp}}$ and initial phase angle between the two frequencies of $0^{\circ}$. These frequencies correspond to a Mathieu stability parameter of $\mathrm{q}_{\mathrm{z}}=0.45$. (Note: the $\mathrm{q}_{\mathrm{z}}$ value discussed henceforth refers to the smaller of the two applied frequencies.) Under these conditions, the $n$-butylbenzene precursor ion undergoes a certain degree of fragmentation and the ion ratio of 91/92 in this case is about 8. The conditions signify that the high internal energy, direct cleavage product is favored. These results indi-

Figure 2. Simulations conducted with ITSIM to show the influence of different excitation waveforms on the total kinetic energy of $n$-butylbenzene ions (134 Th) as a function of time. The ions are excited by a fixed-frequency waveform applied to the end-cap electrodes in dipolar fashion during mass acquisition from LMCO $40-150 \mathrm{Th}$ at a rate of $5.5 \mathrm{Th} / \mathrm{ms}$ : (a) $171 \mathrm{kHz}, 0^{\circ}$ phase angle at 2 $\mathrm{V}_{\mathrm{pp}}$; (b) $172 \mathrm{kHz}, 0^{\circ}$ phase angle at $2 \mathrm{~V}_{\mathrm{pp}}$; (c) $171 \mathrm{kHz}, 0^{\circ}$ phase angle at $2 \mathrm{~V}_{\mathrm{pp}} ; 172 \mathrm{kHz}, 0^{\circ}$ phase angle at $2 \mathrm{~V}_{\mathrm{pp}} ;$ (d) $171 \mathrm{kHz}, 0^{\circ}$ phase angle at $2 \mathrm{~V}_{\mathrm{pp}} ; 172 \mathrm{kHz}, 180^{\circ}$ phase angle at $2 \mathrm{~V}_{\mathrm{pp}}$. In the absence of an applied excitation waveform, the ions are expected to reach a secular frequency of $171 \mathrm{kHz}$ at $5.13 \mathrm{~ms}$. 


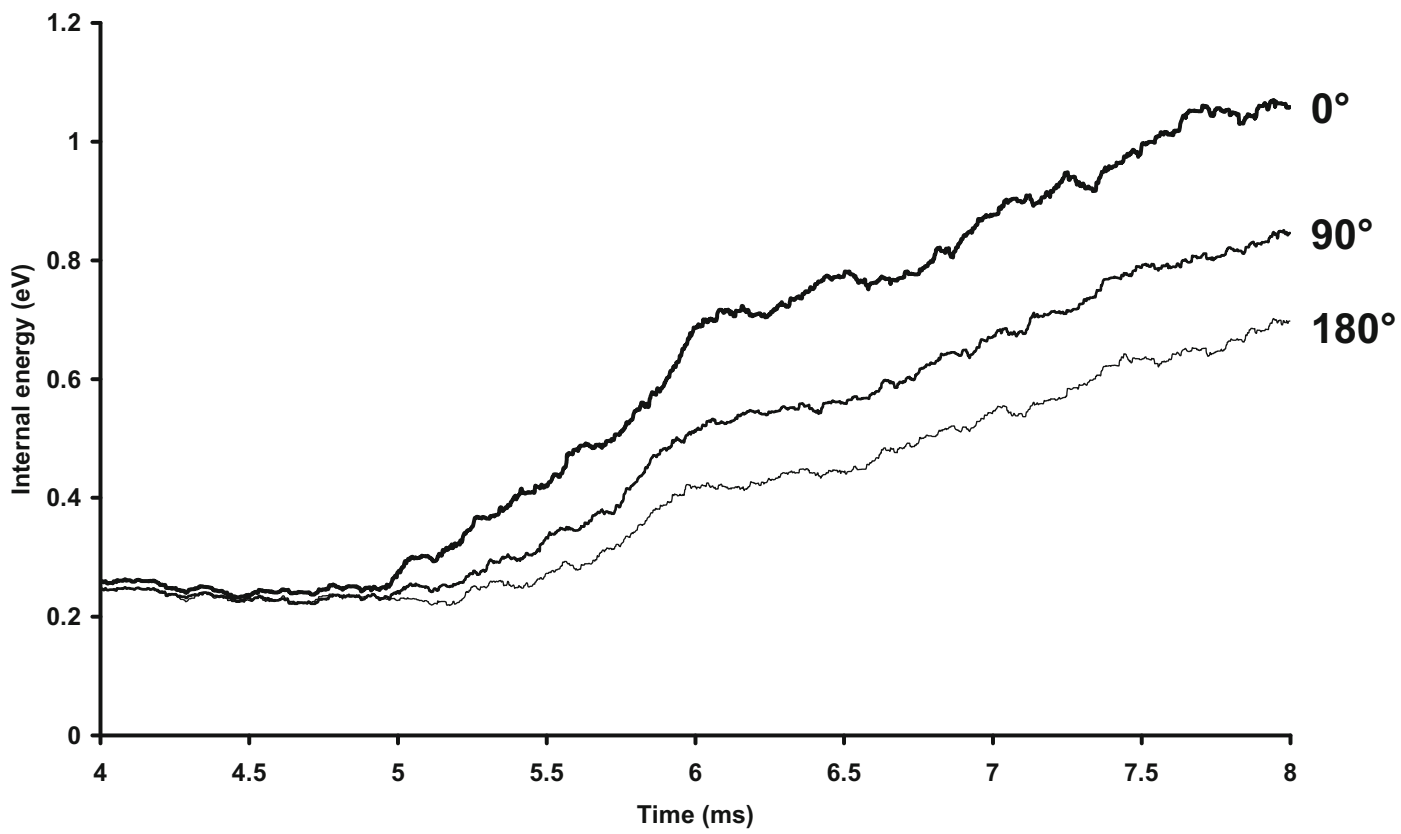

Figure 3. Simulations conducted with ITSIM to show the increase in internal energy as a function of time for $n$-butylbenzene ions that are excited by a two-frequency excitation waveform of $4{ }_{\mathrm{Vpp}}$ during mass acquisition. The labels show the initial phase angle of the excitation frequency at $172 \mathrm{kHz}$ relative the excitation frequency at $171 \mathrm{kHz}$.

cate that the secular frequency of the ions is likely to come into resonance conditions during a crest or max-

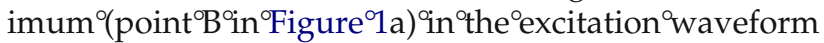
and thus undergoes a significant degree of energy deposition. The large energy deposition results in a large amount of resonance ejection and large 91/92 ratios.

When the initial phase angle between the two frequencies ${ }^{\circ}$ is ${ }^{\circ}$ set $^{\circ}{ }^{\circ}{ }^{\circ} 180^{\circ}\left(\right.$ Figure $\left.^{\circ} 4 \mathrm{~b}\right),{ }^{\circ}$, the ${ }^{\circ}$ mass ${ }^{\circ}$ spectrum changes radically. The excitation waveform at the time of resonance is close to a node in the excitation waveform ${ }^{\circ}$ (point ${ }^{\circ} \mathrm{B}^{\circ}$ in $^{\circ}$ Figure $^{\circ} 1 \mathrm{~b}$ ), ${ }^{\circ}$ the ${ }^{\circ}$ excitation ${ }^{\circ}$ amplitude ${ }^{\circ}$ is much smaller, and thus the resonance ejection is significantly reduced. Under these conditions, the fragmentation efficiency is dramatically improved and the ratio of $91 / 92$ is much smaller, at about 0.9 . In this case, the $\mathrm{C}_{7} \mathrm{H}_{8}{ }^{+}$McLafferty rearrangement product and direct cleavage ${ }^{\circ}$ product ${ }^{\circ}$ are ${ }^{\circ}$ favored ${ }^{\circ}$ almost ${ }^{\circ}$ equally. ${ }^{\circ}{ }^{\circ}{ }^{\circ}$ Figure $4 a,{ }^{\circ}$ resonance ${ }^{\circ}$ ejection $^{\circ}$ of $^{\circ}$ the ${ }^{\circ}$ parent ${ }^{\circ}{ }^{\circ}{ }^{\circ}{ }^{\circ}$ is ${ }^{\circ}$ apparent ${ }^{\circ}$ at the LMCO $67.3 \mathrm{Th}$, which is clearly limiting the CID efficiency.

Figures ${ }^{\circ} 5^{\circ}$ and ${ }^{\circ} 6^{\circ}$ show $^{\circ}$ experimentally ${ }^{\circ}$ determined two-dimensional contour plots of CID efficiency and ion ratios of $91 / 92$, respectively, under different excitation waveform conditions. Again, each plot displays the results of over 13,000 conditions conducted in a single sequence-looped ${ }^{\circ}$ experiment. ${ }^{\circ}$ Figure ${ }^{\circ} \mathrm{a}^{\circ}$ shows ${ }^{\circ}$ the ${ }^{\circ} \mathrm{CID}$ efficiencies obtained when isolated precursor ions of $n$-butylbenzene are exposed at different excitation amplitudes and phase angles with the excitation frequencies applied at 131 and $132 \mathrm{kHz}\left(\mathrm{q}_{\mathrm{z}}=0.35\right)$. At excitation amplitudes $<1.0 \mathrm{~V}_{\mathrm{pp}}$ the fragmentation efficiencies (a)

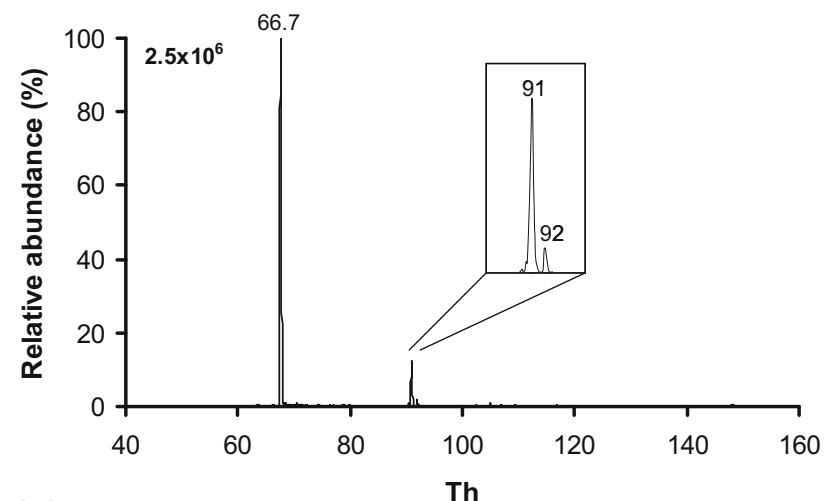

(b)

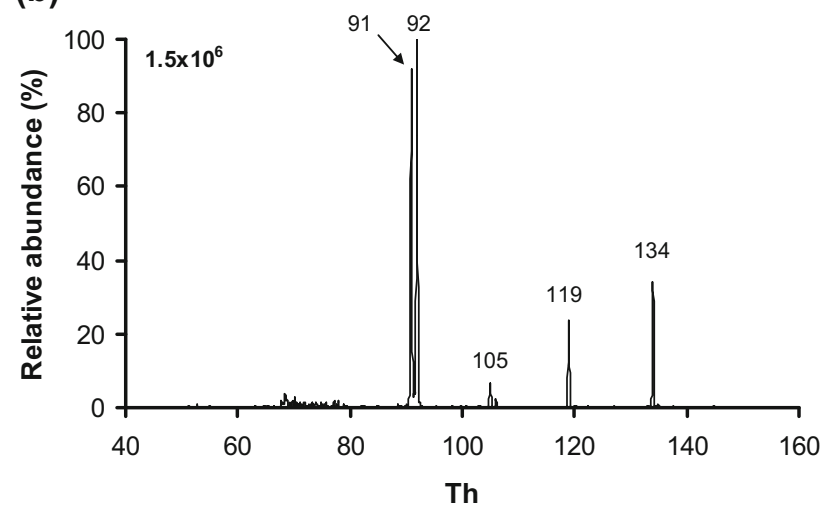

Figure 4. Mass spectra of $n$-butylbenzene when an excitation waveform consisting of 171 and $172 \mathrm{kHz}\left(\mathrm{q}_{\mathrm{z}}=0.45\right)$ is applied during mass acquisition with an excitation amplitude of $4 \mathrm{vpp}_{\mathrm{pp}}(2$ $\mathrm{V}_{\mathrm{pp}}$ on each frequency). The initial phase angle between the first and second excitation frequency is (a) $0^{\circ}$ and (b) $180^{\circ}$. 
(a)

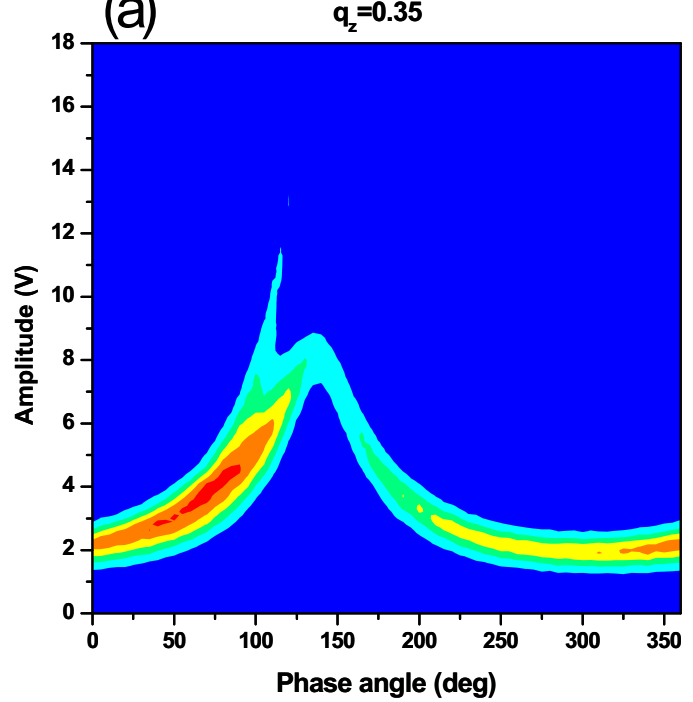

(c)

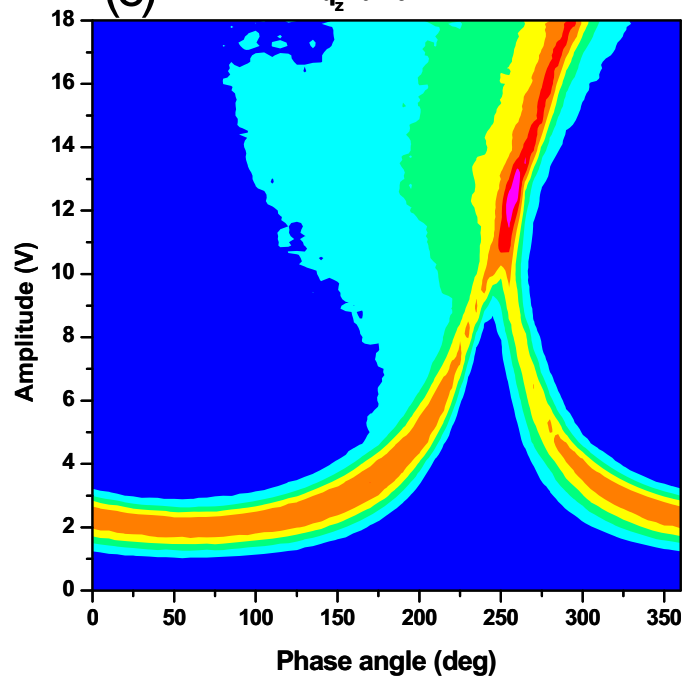

(e)

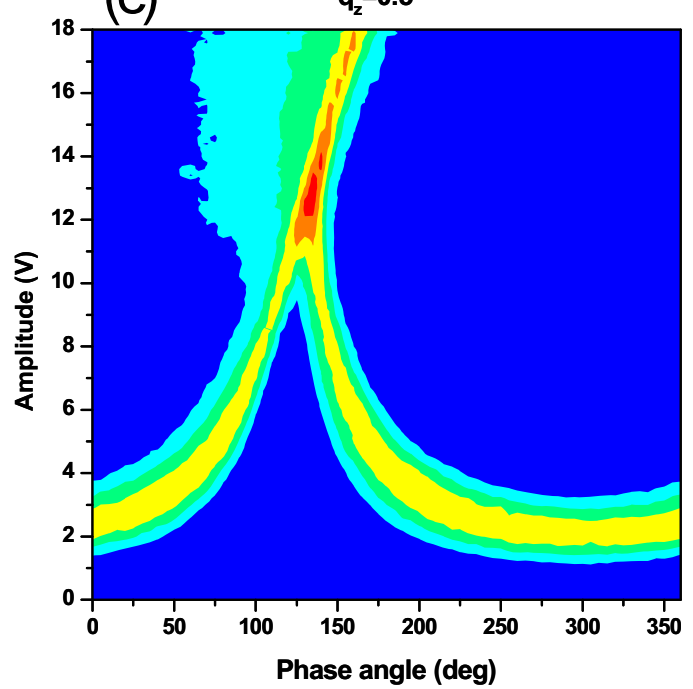

(b) $q_{z}=0.4$

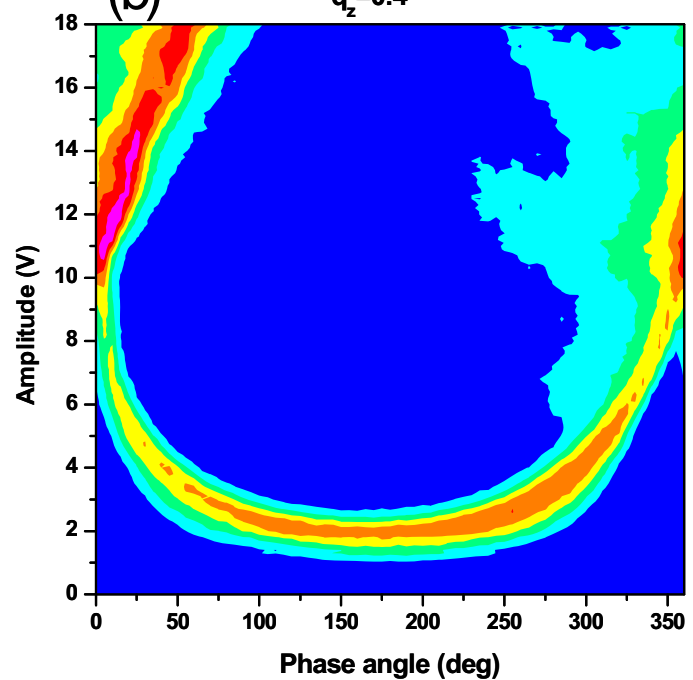

(d)

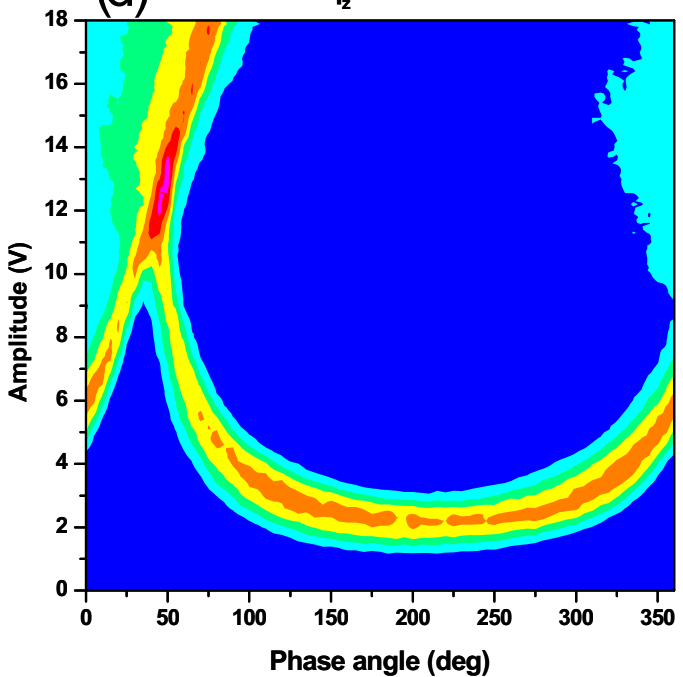

CID efficiency (\%)

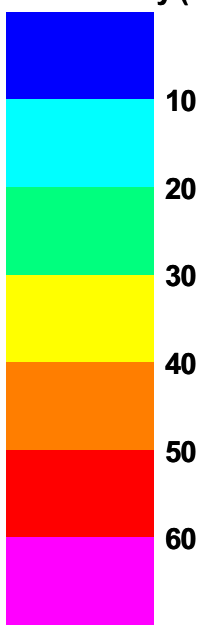

Figure 5. CID efficiency values plotted as a function of amplitude and initial phase angle of the applied two-frequency excitation waveform at (a) $\mathrm{q}_{\mathrm{z}}=0.35 ;(\mathbf{b}) \mathrm{q}_{\mathrm{z}}=0.4 ;$ (c) $\mathrm{q}_{\mathrm{z}}=0.45 ;$ (d) $\mathrm{q}_{\mathrm{z}}=0.47$; (e) $\mathrm{q}_{\mathrm{z}}=0.5\left(\mathrm{q}_{\mathrm{z}}\right.$ values calculated for the smaller of the two frequencies). 
(a)

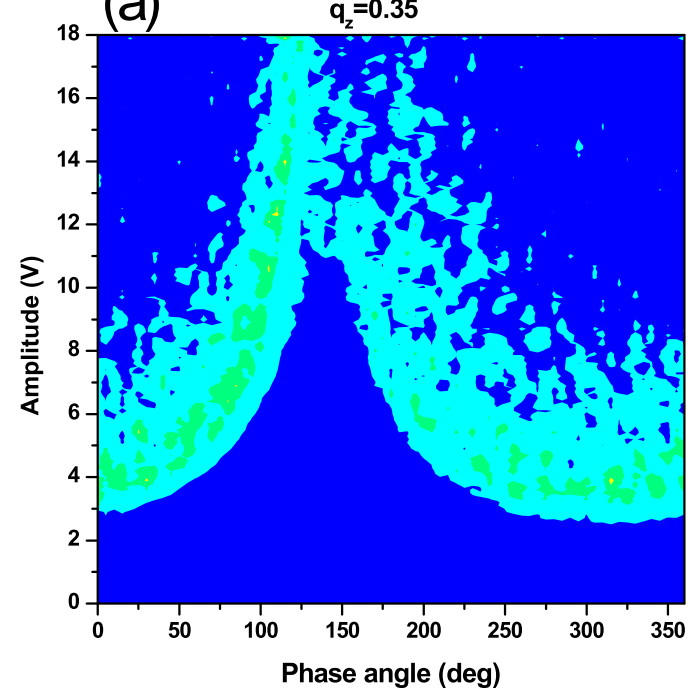

(c)

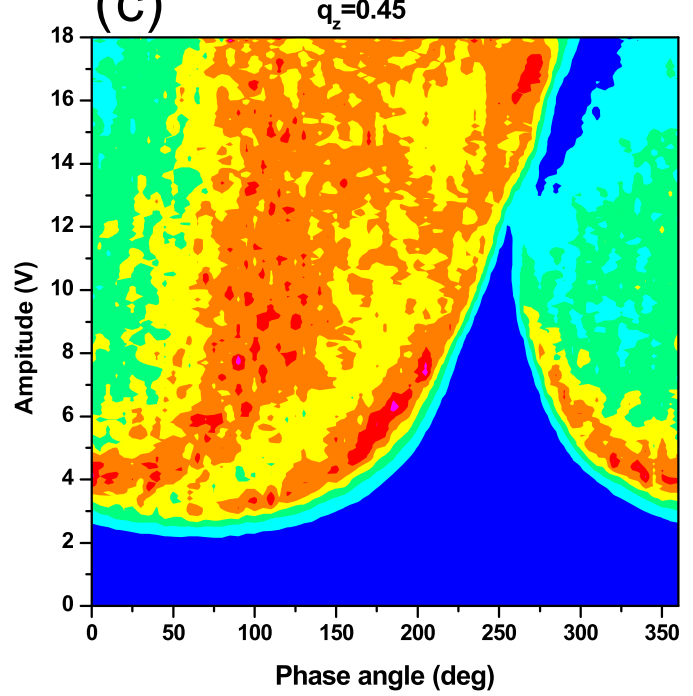

(e)

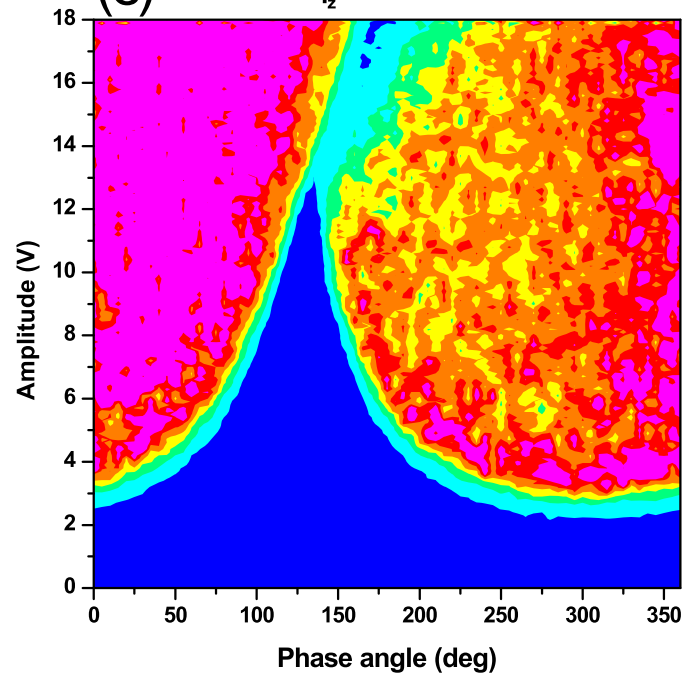

(b)

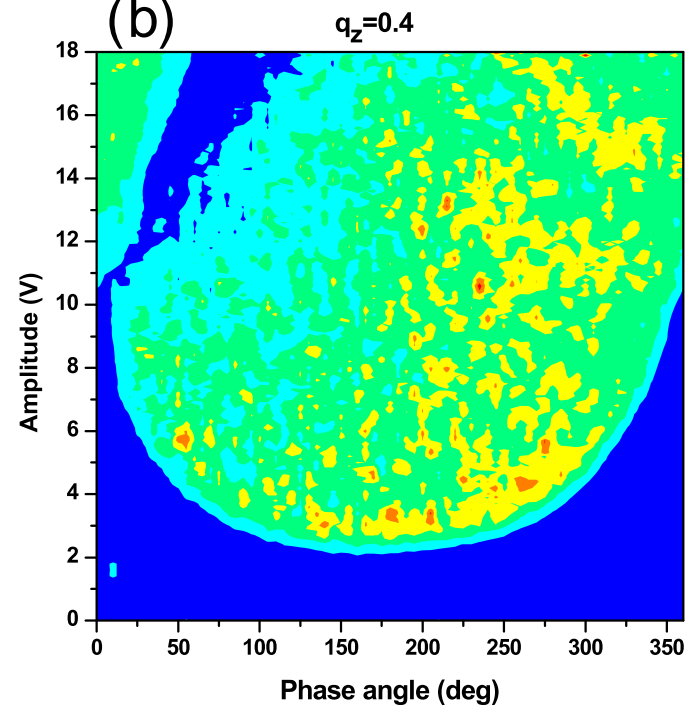

(d)

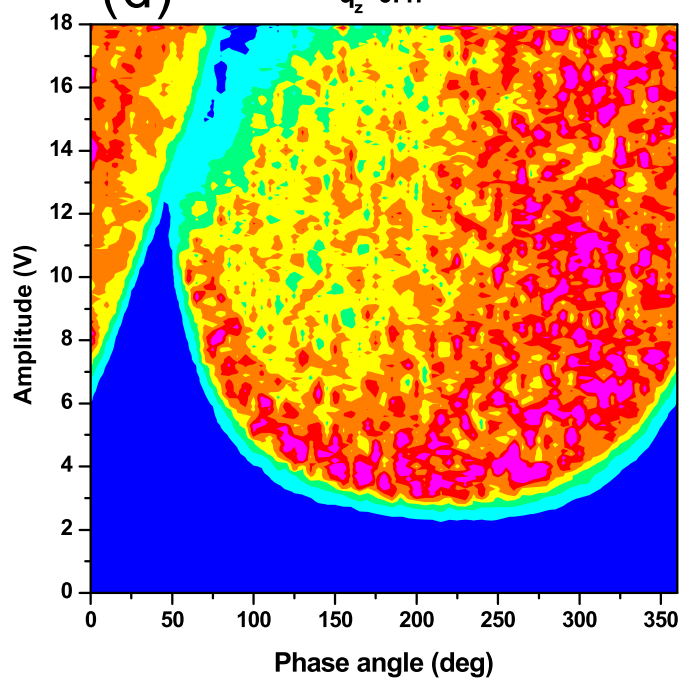

Ratio 91/92

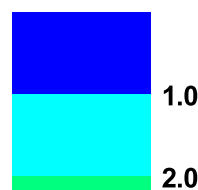

3.0

4.0

5.0

6.0

Figure 6. Ion ratios of 91/92 plotted as a function of amplitude and initial phase angle of the two-frequency excitation waveform at (a) $\mathrm{q}_{\mathrm{z}}=0.35$; (b) $\mathrm{q}_{\mathrm{z}}=0.4 ;$ (c) $\mathrm{q}_{\mathrm{z}}=0.45 ;$ (d) $\mathrm{q}_{\mathrm{z}}=0.47$; (e) $\mathrm{q}_{\mathrm{z}}=$ $0.5\left(\mathrm{q}_{\mathrm{z}}\right.$ values calculated for the smaller of the two frequencies). 
are $<10 \%$. This is in agreement with well-established studies that show that the resonance excitation amplitude must be above a certain threshold to deposit sufficient ${ }^{\circ}$ internal ${ }^{\circ}$ energ $^{\circ}$ to $^{\circ}$ initiate ${ }^{\circ}$ fragmentation ${ }^{\circ}[41$, 42]..$^{\circ}$ Clearly, ${ }^{\circ}$ at ${ }^{\circ}$ excitation ${ }^{\circ}$ mplitudes ${ }^{\circ}<1.0^{\circ} \mathrm{V}_{\mathrm{pp}}$, the ions do not gain enough internal energy to undergo fragmentation. Under these conditions, the ions meet resonance conditions with the crest in the excitation waveform when the relative phase angle of the two excitation frequencies is roughly $330^{\circ}$. Conversely, when the relative phase angle is $150^{\circ}\left(180^{\circ}\right.$ different from $\left.330^{\circ}\right)$ the ions meet the excitation waveform during a node and are not significantly excited or fragmented. At a phase angle of $150^{\circ}$, fragmentation can be induced by increasing the excitation amplitude, which permits significant off-resonance excitation to occur. When resonance conditions occur at high excitation amplitudes, such as $>3$ $\mathrm{V}$, the ions are resonantly ejected because their kinetic energy exceeds the Dehmelt pseudopotential well depth at this $\mathrm{q}_{\mathrm{z}}\left[19,{ }^{\circ} 43\right]^{\circ}$ and $^{\circ}$ the ${ }^{\circ} \mathrm{CID}^{\circ}$ efficiencies ${ }^{\circ}$ are therefore poor. When resonance conditions occur close to a node in the excitation waveform (such as at $140^{\circ}$ ), considerably larger excitation amplitudes are required for the ions to be resonantly ejected. The shape of the ridge in the contour profile of maximum CID efficiency in $^{\circ}$ Figure ${ }^{\circ} \mathrm{a}^{\circ} \mathrm{can}^{\circ}$ therefore ${ }^{\circ} \mathrm{be}^{\circ}$ explained ${ }^{\circ}$ in ${ }^{\circ}$ terms ${ }^{\circ}$ of ${ }^{\circ}$ the interference pattern of the excitation waveform.

The maximum CID efficiency calculated under these conditions $\left(q_{z}=0.35\right)$ is $55 \%$ and is observed at an initial phase angle of $70^{\circ}$ and at an excitation amplitude of $3.8 \mathrm{~V}_{\mathrm{pp}}$. One should note that excitation at initial phase angles of 0 and $360^{\circ}$ are, in principle, no different, which explains the similarity between the fragmentation efficiencies at the extreme ends of each twodimensional plot. The coincidence of the results at 0 and $360^{\circ}$ is testimony to the stability of the system during the course of the experiments. The experiments performed at $360^{\circ}$ of data are typically collected $>8 \mathrm{~h}$ after the data collected at $0^{\circ}$, yet the results are quite similar. Rigorous statistical comparisons between inter- and intrarun repeatability have yet to be performed. However, contour maxima and relative CID efficiencies appeared to be within a 10\% risk-specific dose (RSD) of each other when experiments were repeated several weeks apart.

Figure ${ }^{\circ} \mathrm{b}^{\circ}$ shows $^{\circ}$ the ${ }^{\circ} \mathrm{CID}^{\circ}$ efficiencies ${ }^{\circ}$ obtained ${ }^{\circ}$ when the excitation waveform is constructed from frequencies of 151 and $152 \mathrm{kHz}\left(\mathrm{q}_{\mathrm{z}}=0.4\right)$. The maximum CID efficiency observed in the two-dimensional space of Figure $^{\circ} 5 \mathrm{~b}^{\circ}$ is ${ }^{\circ} 70 \%^{\circ}$ and $^{\circ}$ is ${ }^{\circ}$ observed $^{\circ}$ at $^{\circ}$ an $^{\circ}$ initial $^{\circ}$ phase angle of $10^{\circ}$ and an excitation amplitude of $11.6 \mathrm{~V}_{\mathrm{pp}}$. Figure ${ }^{\circ} b^{\circ}{ }^{\circ}$ shares ${ }^{\circ}$ some $^{\circ}$ common $^{\circ}$ features ${ }^{\circ}$ with ${ }^{\circ}$ Figure ${ }^{\circ} 5 a$ and some differences. One notable difference is that the contours showing the maximum CID efficiencies in Figure $^{\circ} 5 b^{\circ}$ form $^{\circ}$ an $^{\circ}$ extended $^{\circ}$ plateau, ${ }^{\circ}$ thereby ${ }^{\circ}$ forming more of a " $U$ "-shaped curve in the two-dimensional plot. This feature is the result of a shift in the phase dimension of the crests and nodes of the resonance excitation ${ }^{\circ}$ waveform. ${ }^{\circ}$ An ${ }^{\circ}$ added ${ }^{\circ}$ feature ${ }^{\circ}$ s $^{\circ}$ that ${ }^{\circ}{ }^{\circ}{ }^{\circ}$ Figure
$5 b^{\circ} \mathrm{CID}{ }^{\circ}$ efficiencies between $20^{\circ}$ and $30 \% \%^{\circ}$ are ${ }^{\circ}$ bserved ${ }^{\circ}$ at amplitudes as high as $18 \mathrm{~V}_{\mathrm{pp}}$, the largest amplitudes studied..$^{\circ}$ This $^{\circ}$ is $^{\circ}$ in $^{\circ}$ contrast $^{\circ}$ to $^{\circ}$ Figure $^{\circ} 5 a^{\circ}{ }^{\circ}$ where ${ }^{\circ}$ CID efficiencies are very small at excitation amplitudes $>10$ $\mathrm{V}_{\mathrm{pp}}$. This difference is thought to be related to the strength of which the precursor ions are held in the trap, characterized by the Dehmelt pseudopotential well ${ }^{\circ}$ epth $[19,43] .{ }^{\circ} \mathrm{A} t^{\circ} \mathrm{q}_{\mathrm{z}}=0.35$, the ions have a smaller well depth than that at $\mathrm{q}_{\mathrm{z}}=0.4$, and thus the ions are ejected at smaller excitation amplitudes. At larger excitation frequencies and, thus, larger $\mathrm{q}_{\mathrm{z}}$ values and pseudopotential well depths, the ions can be excited with larger-amplitude excitation before resonant ejection occurs. At high $\mathrm{q}_{\mathrm{z}}$ values (that is, $\mathrm{q}_{\mathrm{z}}>0.6$, data not shown) the precursor ions are positioned at a large potential well depth, but the smaller $\mathrm{m} / \mathrm{z}$ precursor ions, such as the dominant 91 and 92 Th ions, fall outside the stability diagram and cannot be recaptured and massanalyzed.

For the excitation waveform applied at 171 and 172 $\mathrm{kHz}\left(\mathrm{q}_{\mathrm{z}^{\circ}}={ }^{\circ} 0.45\right)$, ${ }^{\circ}$ shown ${ }^{\circ}{ }^{\circ}{ }^{\circ}$ Figure ${ }^{\circ} 5 \mathrm{c},{ }^{\circ}$ the ${ }^{\circ} \mathrm{CID}^{\circ}$ efficiency values show a trend very similar to that shown in Figure ${ }^{\circ} b^{\circ} a t^{\circ} q_{z}=0.4$. Again, the " $U$ "-shaped contour lines are shifted in the phase dimension compared to $\mathrm{q}_{\mathrm{z}}$ $=0.4$, indicating that resonance conditions occur with a node when the relative phase angle at 172 is set to about $250^{\circ}$. The maximum calculated efficiency value in this experiment was $70 \%$ and occurred at an excitation amplitude of $12.8 \mathrm{~V}_{\mathrm{pp}}$ and initial phase angle of $260^{\circ}$. Further experiments were conducted for waveforms consisted of $180,181 \mathrm{kHz}\left(\mathrm{q}_{\mathrm{z}}=0.47\right)$ and $193,194 \mathrm{kHz}\left(\mathrm{q}_{\mathrm{z}}\right.$ $=0.5)^{\circ}$ frequencies; ${ }^{\circ}$ the ${ }^{\circ}$ data $^{\circ}$ are $^{\circ}$ shown ${ }^{\circ}{ }^{\circ}$ Figure $5 \mathrm{~d}^{\circ}$ and e. It is apparent that the trends are very similar to those described in the previous instances, although the recorded efficiency values are slightly smaller under these conditions.

In general, it seems that performing CID of $n$ butylbenzene at $\mathrm{q}_{\mathrm{z}}$ parameters between 0.35 and 0.5 provides optimal CID efficiencies compared to $\mathrm{q}_{\mathrm{z}}$ values outside this window. These findings are comparable to observations made using conventional on-resonance $^{\circ}$ excitation $^{\circ}\left[37,{ }^{\circ} 45\right] .^{\circ}$ At $^{\circ}$ smaller $^{\circ} \mathrm{q}_{z}$ parameters, resonance ejection competes with fragmentation arising from the weakness with which the precursor ions are held in the trap at the point of resonance excitation. Again, resonance ejection is confirmed in every case by the observation of an ion signal that corresponded to the LMCO at which the $n$-butylbenzene precursor ion is excited. At $\mathrm{q}_{\mathrm{z}}$ values $>0.5$, the major precursor ions of n-butylbenzene fall outside the stability diagram, which is indistinguishable from resonance excitation. It is apparent that resonance conditions between the ions' dynamic secular frequency and the excitation waveform can be made to occur during a node or crest in the interference pattern of the excitation waveform by careful selection of the phase angle of the two excitation frequencies. When resonance conditions occur during a crest or maximum in the interference pattern, smaller excitation amplitudes are necessary for efficient frag- 
mentation compared to the case when resonance conditions occur during a node or minimum in the interference pattern.

Figure $^{\circ} 6^{\circ}$ shows $^{\circ}$ the ${ }^{\circ}$ ratios $^{\circ}$ of ${ }^{\circ} 91 / 92^{\circ}$ that $^{\circ}$ were $^{\circ}$ calculated from the same mass spectra used to obtain the data ${ }^{\circ}$ presented ${ }^{\circ}{ }^{\circ}{ }^{\circ}$ igure ${ }^{\circ} 5 .{ }^{\circ}$ In ${ }^{\circ}$ general, ${ }^{\circ}$ the ${ }^{\circ}$ shapes ${ }^{\circ}$ of ${ }^{\circ}$ the contours resemble the contours described for the CID efficiency ${ }^{\circ}$ curves $^{\circ}$ in $^{\circ}$ Figure $^{\circ} 5 .^{\circ} \mathrm{One}^{\circ}$ notable ${ }^{\circ}$ difference ${ }^{\circ}$ in each case is that the largest 91/92 ratios, and therefore the largest internal energies, are observed at regions of high-excitation amplitudes where the CID efficiencies are typically $<30 \%$. This illustrates the competition between fragmentation and ejection that is so often observed at large amplitudes of excitation.

The largest ratios calculated where the CID efficiencies exceeded $10 \%$ were as high as 8 for $\mathrm{q}_{\mathrm{z}}=0.47$ and 15 for $\mathrm{q}_{\mathrm{z}}=0.5$. At this point, it is worth noting that the maximum ratio of $91 / 92$ reported for $n$-butylbenzene using conventional on-resonance excitation in a QIT is $4.2^{\circ}[5],{ }^{\circ}$ which $^{\circ}$ corresponds $^{\circ}$ to $^{\circ}$ an $^{\circ}$ internal $^{\circ}$ energy $^{\circ}$ of about $5 \mathrm{eV}$. Using conventional on-resonance excitation at a $\mathrm{q}_{\mathrm{z}}$ of 0.45 , we were not able to obtain 91/92 ratios greater than 3.0 before efficiencies were too poor for reasonable statistics. The fact that this new dynamic approach to effecting CID of precursor ions can achieve ratios of 91/92 as high as 15 is a substantial accomplishment. Product-ion ratios this large were previously reported only once before for $n$-butylbenzene, and that was obtained using dc-pulsed axial excitation in a QIT [15]..$^{\circ}$ The $^{\circ}$ very $^{\circ}$ high $^{\circ}$ energy $^{\circ}$ fragmentations ${ }^{\circ}$ observed using dynamic CID, or pulsed activation, could be useful for inducing the fragmentation of large precursor ions such as intact proteins. This benefit is expected because the extremely rapid heating rate required to reach the high internal energies of $n$-butylbenzene is also required to overcome the fast collisional cooling rates of large bio-ions, which, in addition to an increased number of degrees of freedom, is thought to be one of the limiting factors in fragmenting large ions.

Although independent observation of the CID efficiencies and fragmentation energetics is quite informative, it is often desirable to identify conditions that provide simultaneous highly energetic and highly efficient fragmentation. Although these are unlikely to be met-because of the competition between fragmentation and resonance ejection-a correlation analysis was performed (see experimental section) to easily identify conditions that provide greater than average CID efficiencies and greater than average fragmentation energetics (as determined by the fragment ion ratios of 91/92). The covariances of the CID efficiencies and the product ion ratios of 91/92 are plotted for each $\mathrm{q}_{\mathrm{z}}$ in Figure ${ }^{\circ}$. ${ }^{\circ}$ Positive ${ }^{\circ}$ covariances $^{\circ}$ indicate ${ }^{\circ}$ positive ${ }^{\circ}$ correlations, wherein both parameters are simultaneously larger than average or smaller than average. The term "average" refers to the mean of the experimental results for a given set of experiments (such as the mean of 13,213 experiments). Negative values represent anticorrelations, such as when the CID efficiency is large and the ion ${ }^{\circ}$ ratios ${ }^{\circ}{ }^{\circ} 91 / 92^{\circ}$ are $^{\circ}$ small. In Figure $7 a-\mathcal{Q}$, the first feature to notice is the anti-correlation represented by the dark blue lines along the zones where the CID efficiency has the largest values. This correlation occurs because the most efficient CID conditions are usually satisfied when the excitation amplitude is relatively small and internal energies barely exceed the threshold for fragmentation and are thus much smaller than average. The positive correlations at small voltages are explained by inefficient and low-energy fragmentations, which-in the context of attempting to achieve CID - is highly undesirable. The regions of interest are areas of positive correlation at higher excitation amplitudes, where large internal energies are known to occur. For the $\mathrm{q}_{\mathrm{z}^{\circ}}=0.35^{\circ}$ experiment ${ }^{\circ}$ shown in Figure $\% \mathrm{a}$, all the positive correlation coefficients indicate experimental conditions where inefficient CID and low internal energy fragmentation occur simultaneously. Exciting ions at this low stability parameter obviously does not offer conditions for simultaneous efficient and highly energetic fragmentation. This trend is related to the observation that the distribution of internal energies (as measured by the standard deviation of the ratios of 91/92) covers a smaller range than that at larger stability parameters.

Figure ${ }^{\circ} 7 b^{\circ}$ shows ${ }^{\circ}$ that ${ }^{\circ}$ when $^{\circ}$ ions $^{\circ}$ are $^{\circ}$ excited ${ }^{\circ}$ during mass acquisition using the two-frequency excitation waveform at $\mathrm{q}_{\mathrm{z}}=0.4$, large areas of positive correlation, indicated by the yellow areas, can be found. The area of positive correlation at $\mathrm{q}_{\mathrm{z}}=0.4$ shows conditions where CID efficiencies are $10-20 \%$ and $91 / 92$ ratios are typically between 3 and 4 . These regions are observed at excitation amplitudes $>5 \mathrm{~V}_{\mathrm{pp}}$ for initial phase angles $>$ $275^{\circ}$ and $<45^{\circ}$. The positive correlations that appear at initial phase angles between 20 and $150^{\circ}$ arise from the low-energy and inefficient fragmentation conditions, as can $^{\circ}$ be $^{\circ}$ seen $^{\circ}$ by $^{\circ}$ observing $^{\circ}$ Figures $^{\circ} 5 b^{\circ}$ and ${ }^{\circ} 6 b$.

Figure $7 c^{\circ}$ shows the ${ }^{\circ}$ ovariances for ${ }^{\circ}$ CID $^{\circ}$ performed at $\mathrm{q}_{\mathrm{z}}=0.45$. The positive correlations indicated by the yellow area at initial phase angles $>260^{\circ}$ and excitation amplitudes $>4 \mathrm{~V}_{\mathrm{pp}}$ are attributed to simultaneously inefficient and low-energy fragmentations, as demonstrated by $^{\circ}$ Figures $5 c^{\circ}$ and $6 c$. The ${ }^{\circ}$ region ${ }^{\circ}$ of interest is the very strong positive correlation that appears at initial phase angles between 225 and $275^{\circ}$ at excitation amplitudes $>11 \mathrm{~V}_{\mathrm{pp}}$. Here, the large CID efficiencies and high ion ratios of 91/92 indicate optimal experimental conditions for both efficient and energetic fragmentations for ions of mass/charge of 134 Th. Here, typical CID efficiencies are $40-50 \%$ and ratios of Th $91 / 92$ are between 5.0 and 6.0. The CID efficiency under these highly energetic conditions is a substantial improvement over conventional resonance excitation, which, at best, can achieve efficiencies of only roughly $10 \%$ under such highly energetic fragmentation conditions.

The covariances calculated for the excitation waveforms applied at $\mathrm{q}_{\mathrm{z}}$ values of 0.47 and 0.5 are shown in Figure ${ }^{\circ} 7 \mathrm{~d}^{\circ}$ and ${ }^{\circ} \mathrm{e}^{\circ}{ }^{\circ}$ respectively. ${ }^{\circ}$ The $^{\circ}$ areas $^{\circ}$ where ${ }^{\circ}$ the experimental conditions are ideal for both efficient and 
(a)

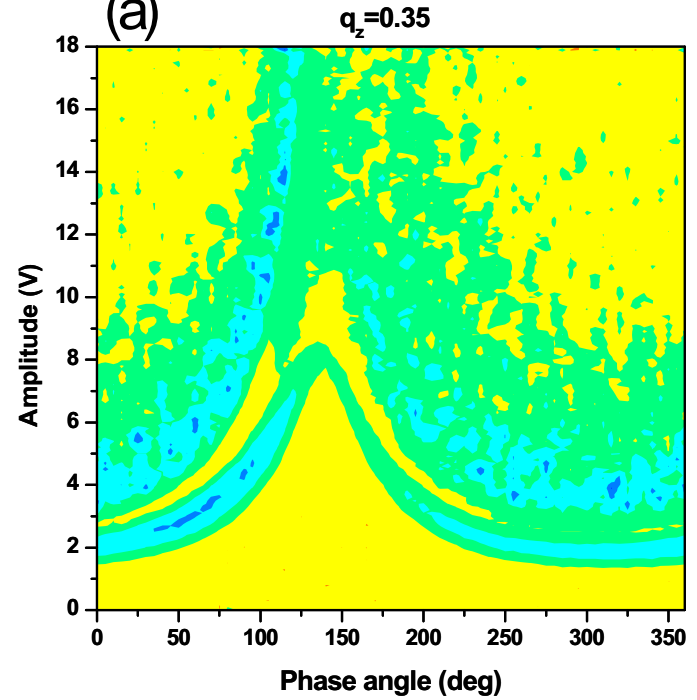

(c)

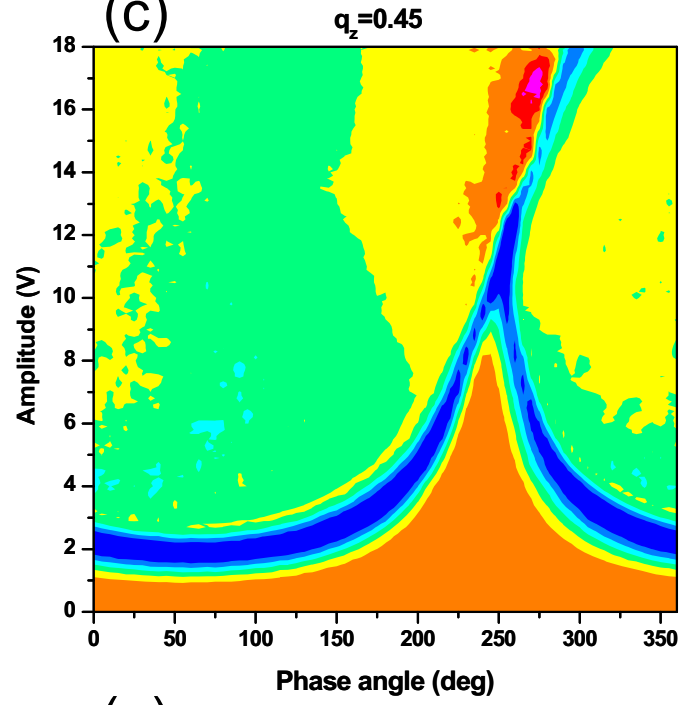

(e)

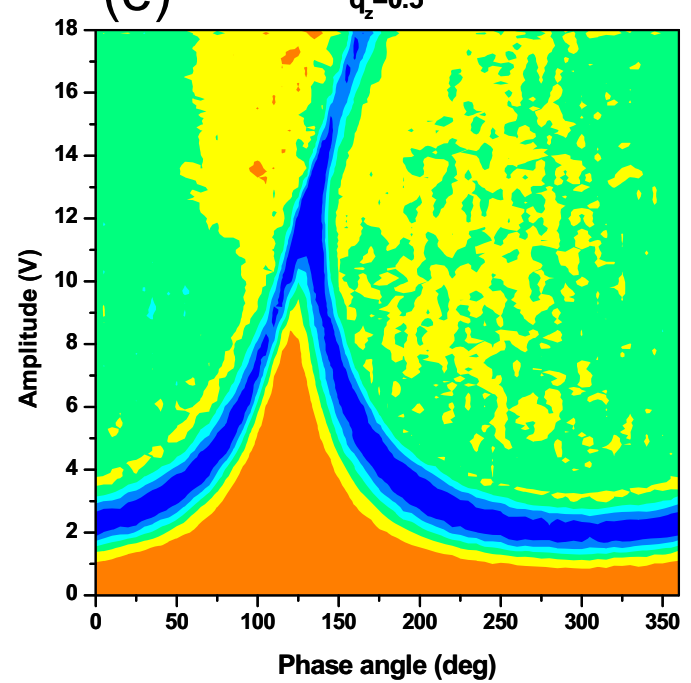

(b)

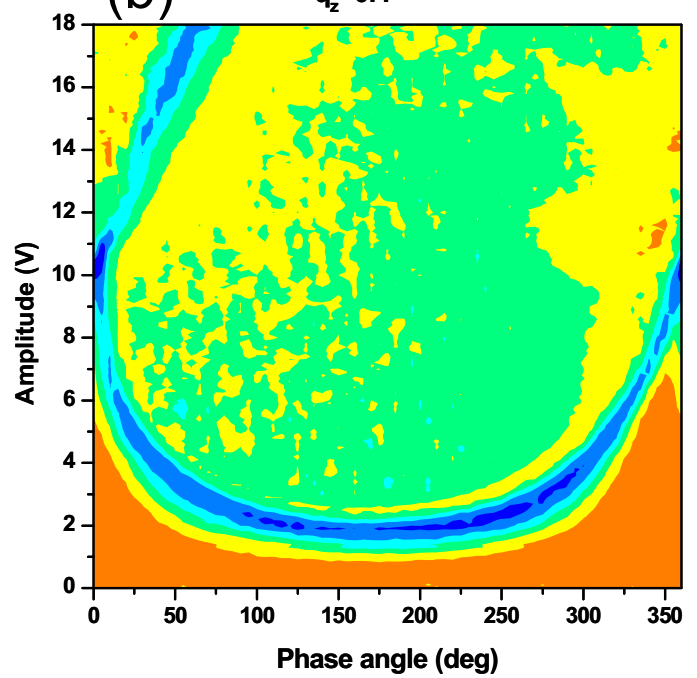

(d)

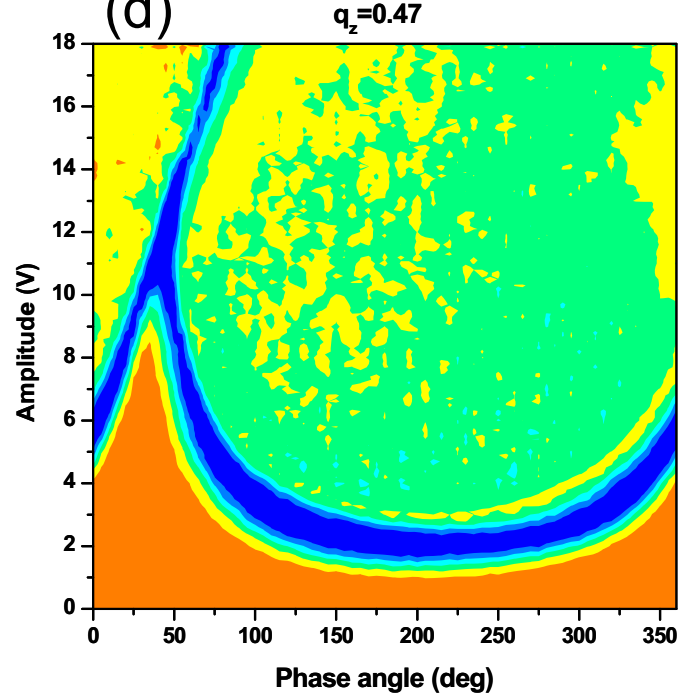

Covariance

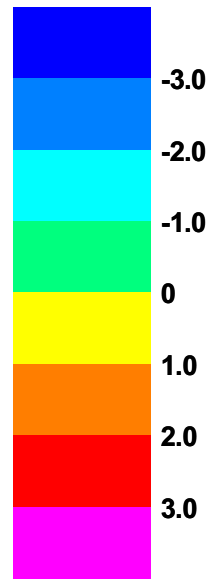

Figure 7. Covariance values of the CID efficiencies and ion ratios of 91/92 plotted as a function of excitation amplitude and initial phase angle between the two frequencies of the applied waveform at (a) $\mathrm{q}_{\mathrm{z}}=0.35 ;(\mathbf{b}) \mathrm{q}_{\mathrm{z}}=0.4 ;$ (c) $\mathrm{q}_{\mathrm{z}}=0.45 ;(\mathbf{d}) \mathrm{q}_{\mathrm{z}}=0.47 ;(\mathbf{e}) \mathrm{q}_{\mathrm{z}}=0.5\left(\mathrm{q}_{\mathrm{z}}\right.$ values calculated for the smaller of the two frequencies). 
energetic fragmentations lay adjacent to the areas where the largest CID efficiencies can be obtained, as seen in Figure ${ }^{\circ} 5 \mathrm{~d}^{\circ}$ and $^{\circ} \mathrm{e} .{ }^{\circ}$ For $^{\circ}$ excitation $^{\circ}{ }^{\circ}{ }^{\circ} \mathrm{q}_{\mathrm{z}}=0.47$ the optimal region stretches between 0 and $60^{\circ}$ at amplitudes $>8$ $\mathrm{V}_{\mathrm{pp}}$, whereas the other areas of positive correlations are the result of less efficient and unenergetic conditions.

\section{Conclusions}

In summary, we have demonstrated that the selected precursor ion of $n$-butybenzene can be deliberately fragmented-and the product ions can be mass analyzed-by subjecting the precursor ions to a twofrequency sum-of-sines waveform during the normal mass acquisition scan of a QIT mass spectrometer. The initial phase relationship between the two excitation frequencies determines whether the excitation waveform is at a node or crest (or somewhere in between) during resonance conditions. The initial phase relationship is a convenient way to define the experimental excitation waveform, but this correlates in a relative way only to the phase-dependent motion of the ions in the trap. At this time, the absolute phase relationships between the motion of the ions and the two excitation waveforms are not known. Qualitatively, simulations using ITSIM support the experimental observations that the internal energy deposition is related to the initial phase angle of the excitation frequencies, but the simulations underestimate the magnitude of the acquired internal energy of the ions.

Because precursor ions of different $m / z$ values move through the stability diagram at different rates, and therefore through the frequency domain at different rates, the phase dependency for ions of different $\mathrm{m} / \mathrm{z}$ values is likely to be different. Indeed, experiments using precursor ions of different perfluorotributylamine fragments and different analogues of $n$-alkylbenzenes and alkyl phenols suggest that the phase dependency is different for ions with different $\mathrm{m} / \mathrm{z}$ values (unpublished results).

The new approach to applying excitation waveforms, dubbed dynamic CID (DCID), has several advantages over conventional CID: (1) resonance tuning with the first excitation frequency is not required because the ions are guaranteed to be on resonance at some time during the mass acquisition scan; (2) no additional scan functions or time is required to achieve the fragmentation of precursor ions, which therefore makes DCID faster to accomplish than conventional CID; (3) precursor ions can be excited to internal energies that are dramatically larger than conventional CID; and (4) multiple precursor ions can be excited in a single experiment, with all the above benefits, with the caveat that the product ion spectrum will require "intelligent" deconvolution to pair product ions with the precursors.

Now, there are also several disadvantages that may or may not have severe implications for implementation in commercial instruments. (1) Somewhat specialized software is required to apply the tailored waveforms during mass acquisition. It seems that most vendors do support the application of custom waveforms during other periods of the scan function, so the hardware in most commercial instruments is not the limiting factor. (2) Many of the conditions for excitation in DCID are coupled to the mass acquisition process, which means that optimal parameters might have to be compromised (mass acquisition scan rates that achieve best CID efficiency might provide poor mass resolution). (3) Operation at large $\mathrm{q}_{\mathrm{z}}$ values, which provides most optimum energy deposition, severely limits the ability to recapture low-mass product ions. (4) The use of two similar excitation frequencies currently requires similar amounts of experimental tuning to the resonance tuning required for conventional on-resonance excitation. In this regard, it seems that the motivation for exploring this method of excitation-which was to simplify tuning requirements-has not been met. However, the companion paper to this, which studies the frequency spacing between the two excitation waveforms, indicates that there are conditions in which the phase dependency can be appreciably reduced or alleviated. Also, the disadvantages labeled (2) and (3) above could presumably be overcome by performing the DCID experiment in a separate scan function and decreasing the primary rf amplitude immediately after excitation of the precursor ions. Thus, excitation of ions would be achieved at large LMCO values and collection of product ions would be achieved at lower LMCO values. The DCID process could then be followed by the mass acquisition scan in the normal fashion. This approach would be very similar to the HASTE experiments described ${ }^{\circ}$ by $^{\circ} \mathrm{Glish}^{\circ}$ and $^{\circ} \operatorname{coworkers}^{\circ}[16]$, except $^{\circ}$ for $^{\circ}$ the dynamic nature of energy deposition.

Large molecules are known to have significantly larger collisional cooling rates than small molecules, which in the past has hindered the ability to fragment large molecules using collisional activation. The rapid rates of internal energy deposition that have been demonstrated in this report suggest that this new approach for collisional excitation could be profoundly beneficial for large molecules such as peptides and proteins. Indeed, recent experiments suggest that very high internal energies can also be obtained for the singly charged precursor ion of leucine enkephalin when excited with single- or two-frequency excitation during mass acquisition (these results are subject of a future publication). We are currently establishing the effects of other instrumental variables-such as scan rate, ion number density, and the difference in frequency between the two excitation waveforms-on the fragmentation ${ }^{\circ}$ behavior $^{\circ}$ of $^{\circ}$ ions ${ }^{\circ}[44]$.

\section{Acknowledgments}

The authors thank Olivier Collin for assistance with the VB programming, Peter B. Harrington for assistance with the correlation analyses, and the Cooks group at Purdue University for the 
use of the ITSIM 5.0 software. Their appreciation is extended to Reviewer \#1 for suggestions regarding data interpretation and understanding of the phenomena involved. The authors also gratefully acknowledge The Office of the Vice President for Research, the College of Arts and Sciences at Ohio University, and the Research Corporation for funding.

\section{References}

1. Steiner, V.; Beaugrand, C.; Liere, P.; Tabet, J.-C. Influence of Trapping Parameters on Ion Injection and Dissociation Efficiencies in a Quadrupole Mass Filter Ion Trap Tandem Instrument. J. Mass Spectrom. 1999, $34,511-520$.

2. Doroshenko, V. M.; Cotter, R. J. Injection of Externally Generated Ions into an Increasing Trapping Field of a Quadrupole Ion Trap Mass Spectrometer. J. Mass Spectrom. 1997, 32, 602-615.

3. Goeringer, D. E.; Asano, K. G.; McLuckey, S. A.; Hoekman, D.; Stiller, S. W. Filtered Noise Field Signals for Mass-selective Accumulation of Externally Formed Ions in a Quadrupole Ion Trap. Anal. Chem. 1994, 66, 313-318

4. Sarurkar, V. A.; Menon, A. G. Vector Summed Sine Wave Tailored Waveforms for Dipolar Excitation of Ions in Paul Trap Mass Spectrometers. Rapid Commun. Mass Spectrom. 1999, 13, 469-473.

5. Louris, J. N.; Cooks, R. G.; Syka, J. E. P.; Kelley, P. E.; Stafford, G. C.; Todd, J. F. J., Instrumentation, Applications, and Energy Deposition in Quadrupole Ion-Trap Tandem Mass-Spectrometry. Anal. Chem. 1987, 59, 1677-1685.

6. Splendore, M.; Lausevic, M.; Lausevic, Z.; March, R. E., Resonant Excitation and/or Ejection of Ions Subjected to DC and RF Fields in a Commercial Quadrupole Ion Trap. Rapid Commun. Mass Spectrom. 1997, 11, 228-233

7. Splendore, M.; Marquette, E.; Oppenheimer, J.; Huston, C.; Wells, G. A New Ion Ejection Method Employing an Asymmetric Trapping Field to Improve the Mass Scanning Performance of an Electrodynamic Ion Trap. Int. J. Mass Spectrom. 1999, 191, 129-143.

8. McClellan, J. E.; Quarmby, S. T.; Yost, R. A., Parent and Neutral Loss Monitoring on a Quadrupole Ion Trap Mass Spectrometer: Screening of Acylcarnitines in Complex Mixtures. Anal. Chem. 2002, 74, 5799-5806.

9. Goeringer, D. E.; Whitten, W. B.; Ramsey, J. M.; McLuckey, S. A.; Glish, G. L. Theory of High-resolution Mass-Spectrometry Achieved via Resonance Ejection in the Quadrupole Ion Trap. Anal. Chem. 1992, 64, 1434-1439.

10. Hao, C. Y.; March, R. E. A Survey of Recent Research Activity in Quadrupole Ion Trap Mass Spectrometry. Int. J. Mass Spectrom. 2001, 212, 337-357.

11. Cox, K. A.; Williams, J. D.; Cooks, R. G.; Kaiser, R. E. Quadrupole Ion Trap Mass-Spectrometry-Current Applications and Future Directions for Peptide Analysis. Biol. Mass Spectrom. 1992, 21, 226-241.

12. Fulford, J. E.; Hoa, D. N.; Hughes, R. J.; March, R. E.; Bonner, R. F.; Wong, G. J., Radio-Frequency Mass Selective Excitation and Resonant Ejection of Ions in a 3-Dimensional Quadrupole Ion Trap. J. Vac. Sci. Technol. 1980, 17, 829-835.

13. Goeringer, D. E.; McLuckey, S. A. Evolution of Ion Internal Energy during Collisional Excitation in the Paul Ion Trap: A Stochastic Approach. J. Chem. Phys. 1996, 104, 2214-2221.

14. McLuckey, S. A. Principles of Collisional Activation in Analytical Mass-Spectrometry. J. Am. Soc. Mass Spectrom. 1992, 3, 599-614.

15. Lammert, S. A.; Cooks, R. G. Pulsed Axial Activation in the Ion Trap-A New Method for Performing Tandem Mass-Spectroscopy (MS/MS). Rapid Commun. Mass Spectrom. 1992, 6, 528-530.

16. Cunningham, C.; Glish, G. L.; Burinsky, D. J. High Amplitude Short Time Excitation: A Method to Form and Detect Low Mass Product Ions in a Quadrupole Ion Trap Mass Spectrometer. J. Am. Soc. Mass Spectrom. 2006, 17, 81-84.

17. Murrell, J.; Despeyroux, D.; Lammert, S. A.; Stephenson, J. L.; Goeringer, D. E. "Fast Excitation" CID in a Quadrupole Ion Trap Mass Spectrometer. J. Am. Soc. Mass Spectrom. 2003, 14, 785-789.

18. March, R. E.; Todd, F. J. Quadrupole Ion Trap Mass Spectrometry, 2nd ed. John Wiley \& Sons: New York, 2005; Vol. 165.

19. Charles, M. J.; McLuckey, S. A.; Glish, G. L. Competition between Resonance Ejection and Ion Dissociation during Resonance Excitation in a Quadrupole Ion Trap. J. Am. Soc. Mass Spectrom. 1994, 5, 1031-1041.

20. Kaiser, R. E.; Cooks, R. G.; Stafford, G. C.; Syka, J. E. P.; Hemberger, P. H. Operation of a Quadrupole Ion Trap Mass-Spectrometer to Achieve High Mass Charge Ratios. Int. J. Mass Spectrom. Ion Process. 1991, 106, 79-115
21. Creaser, C. S.; Stygall, J. W. A Comparison of Overtone and Fundamental Resonances for Mass Range Extension by Resonance Ejection in a Quadrupole Ion Trap Mass Spectrometer. Int. J. Mass Spectrom. 1999, 191, 145-151.

22. McClellan, J. E.; Murphy, J. P.; Mulholland, J. J.; Yost, R. A. Effects of Fragile Ions on Mass Resolution and on Isolation for Tandem Mass Spectrometry in the Quadrupole Ion Trap Mass Spectrometer. Anal. Chem. 2002, 74, 402-412.

23. Favre, A.; Gonnet, F.; Tabet, J.-C. Perturbation of Ion Trajectories by Resonant Excitation Leads to Occurrence of Ghost Peaks. Rapid Commun. Mass Spectrom. 2001, 15, 446-450.

24. Murphy, J. P.; Yost, R. A. Origin of Mass Shifts in the Quadrupole Ion Trap: Dissociation of Fragile Ions Observed with a Hybrid Ion Trap/ Mass Filter Instrument. Rapid Commun. Mass Spectrom. 2000, 14, 270 273

25. Dobson, G.; Murrell, J.; Despeyroux, D.; Wind, F.; Tabet, J. C. Investigations into the Use of a Reverse Scan in a Quadrupole Ion Trap Mass Spectrometer. Rapid Commun. Mass Spectrom. 2003, 17, 1657-1664.

26. Williams, J. D.; Cox, K. A.; Cooks, R. G.; McLuckey, S. A.; Hart, K. J.; Goeringer, D. E. Resonance Ejection Ion-Trap Mass-Spectrometry and Nonlinear Field Contributions-The Effect of Scan Direction on Mass Resolution. Anal. Chem. 1994, 66, 725-729.

27. Wells, J. M.; Plass, W. A.; Cooks, R. G. Control of Chemical Mass Shifts in the Quadrupole Ion Trap through Selection of Resonance Ejection Working Point and rf Scan Direction. Anal. Chem. 2000, 72, 2677-2683.

28. Dobson, G.; Murrell, J.; Despeyroux, D.; Wind, F.; Tabet, J.-C. Investigation into Factors Affecting Precision in Ion Trap Mass Spectrometry Using Different Scan Directions and Axial Modulation Potential Amplitudes. J. Mass Spectrom. 2004, 39, 1295-1304.

29. Jackson, G. P.; King, F. L.; Duckworth, D. C. Efficient Polyatomic Interference Reduction in Plasma-source Mass Spectrometry via Collision Induced Dissociation. J. Anal. At. Spectrom. 2003, 18, 1026-1032.

30. Jackson, G. P.; Hyland, J. J.; Laskay, U. A. Energetics and Efficiencies of Collision-induced Dissociation Achieved during the Mass Acquisition Scan in a Quadrupole Ion Trap. Rapid Commun. Mass Spectrom. 2005, 19, 3555-3563.

31. Baer, T.; Dutuit, O.; Mestdagh, H.; Rolando, C. Dissociation Dynamics of Normal-Butylbenzene Ions-The Competitive Production of $\mathrm{m} / \mathrm{z}$ 91-Fragment and 92-Fragment Ions. J. Phys. Chem. 1988, 92, 5674-5679.

32. Griffiths, I. W.; Harris, F. M.; Mukhtar, E. S.; Beynon, J. H. Calculation of the Abundance Ratio [91+92+] from Normal-Butylbenzene Molecular-Ions as a Function of Internal Energy. Int. J. Mass Spectrom. Ion Process. 1981, 41, 83-88.

33. Harrison, A. G.; Lin, M. S. Energy-dependence of the Fragmentation of the Normal-Butylbenzene Molecular Ion. Int. I. Mass Spectrom. Ion Process. 1983, 51, 353-356.

34. Oh, S. T.; Choe, J. C.; Kim, M. S. Photodissociation Dynamics of n-Butylbenzene Molecular Ion. J. Phys. Chem. 1996, 100, 13367-13374.

35. Plomley, J. B.; Londry, F. A.; March, R. E. The Consecutive Fragmentation of $n$-Butylbenzene in a Quadrupole Ion Trap. Rapid Commun. Mass Spectrom. 1996, 10, 200-203.

36. Dawson, P. H. Low-energy Collision-activated Dissociation of $n$-Butylbenzene. Effect of the Electron Energy Used during Parent Ion Formation. Int. J. Mass Spectrom. Ion Process. 1985, 63, 339.

37. Liere, P.; March, R. E.; Blasco, T.; Tabet, J.-C. Resonance Excitation in a Quadrupole Ion Trap: Modification of Competing Dissociative Channel Yields. Int. J. Mass Spectrom. Ion Process. 1996, 153, 101-117.

38. Chen, J. H.; Hays, J. D.; Dunbar, R. C. Competitive 2-Channel Photodissociation of Normal-Butylbenzene Ions in the Fourier-Transform Ion-Cyclotron Resonance Mass-Spectrometer. J. Phys. Chem. 1984, 88, 4759-4764.

39. McClave, J. T.; Dietrich, F. H. Statistics, 3rd ed.; Dellen Publishing Company: San Francisco, CA, 1985.

40. Bui, H. A.; Cooks, R. G. Windows Version of the Ion Trap Simulation Program ITSIM: A Powerful Heuristic and Predictive Tool in Ion Trap Mass Spectrometry. J. Mass Spectrom. 1998, 33, 297-304.

41. Hart, K. J.; McLuckey, S. A. Relative Dissociation Energy Measurements Using Ion Trap Collisional Activation. J. Am. Soc. Mass Spectrom. 1994, 5, 250-259.

42. Colorado, A.; Brodbelt, J. An Empirical Approach to Estimation of Critical Energies by Using a Quadrupole Ion Trap. J. Am. Soc. Mass Spectrom. 1996, 7, 1116-1125.

43. Vedel, F. On the Dynamics and Energy of Ion Clouds Stored in an rf Quadrupole Trap. Int. J. Mass Spectrom. Ion Process. 1991, 106, 33-61.

44. Wang, M. D.; Schachterle, S.; Wells, G. Application of Nonresonance Excitation to Ion Trap Tandem Mass Spectrometry and Selected Ejection Chemical Ionization. J. Am. Soc. Mass Spectrom. 1996, 7, 668-676.

45. Paradisi, C.; Todd, J. F. J.; Vettori, U. Comparison of Collisional Activation by the Boundary Effect vs Tickle Excitation in an Ion Trap Mass-Spectrometer. Org. Mass Spectrom. 1992, 27, 1210-1215. 